\title{
Medial Nucleus of the Amygdala in the Adult Syrian Hamster: A Quantitative Golgi Analysis of Gonadal Hormonal Regulation of Neuronal Morphology
}

\author{
DIANA M. GOMEZ AND SARAH WINANS NEWMAN \\ Department of Anatomy and Cell Biology, University of Michigan, Ann Arbor, Michigan
}

\begin{abstract}
The medial nucleus of the amygdala (Me) processes both chemosensory and hormonal input. In the male Syrian hamster the integrity of this nucleus is essential for normal reproductive behavior. To determine if gonadal steroids modulate neuronal structure in this nucleus, the morphology of Golgistained neurons in the anterior and posterior regions of Me were compared in castrated and reproductively intact adult hamsters.

In castrated males, neurons in the posterior, but not the anterior, region of $\mathrm{Me}$ undergo structural changes, as indicated by a decrease in the mean highest dendritic branch level and mean somal area compared to intact males. To further elucidate the importance of testosterone and its metabolites in maintenance of neuronal structure in the adult, seven groups of male Syrian hamsters were studied. Animals were castrated and received a blank silastic capsule or a capsule filled with either testosterone, dihydrotestosterone, or estradiol, or two capsules containing both metabolites, dihydrotestosterone and estradiol. Two groups of reproductively intact animals were included: brains from one group were processed simultaneously with the castrated and hormone-treated groups (control intact group), and the other group was processed at the beginning of the experiment. Animals were tested for mating behavior and flank glands were measured to test whether the capsules were effective in releasing the hormones into circulation. After a 12 -week survival period, the brains were processed with Golgi stain and wellimpregnated neurons from the posterior Me were quantitatively analyzed for somal area, highest dendritic branch, total dendritic length, and density of spines. All the measures analyzed revealed a consistent pattern of response to the different gonadal steroids. Castration resulted in a decrease in the mean somal area, the mean highest dendritic branch, and the percentage of neurons with tertiary branch segments. Dihydrotestosterone treatment also resulted in a significant decrease in somal area, mean highest dendritic branch, and percentage of neurons with tertiary dendritic branches. In addition, the total dendritic length and spine density on terminal dendrites were reduced in these brains. The remaining hormone treatment groups were not significantly different from the control group. These results suggest that in orchidectomized male Syrian hamsters, testosterone or its aromatized form, estradiol, but not dihydrotestosterone, is sufficient to maintain the normal morphology of the neurons in the posterior part of the medial nucleus of the amygdala.
\end{abstract}

Gonadal hormones have been shown to be involved in organizing the neural circuits of the developing central nervous system (Goy and McEwen, 1980; Arnold and Breedlove, 1985; Arnold and Jordan, 1988). As summarized by Torand-Allerand (1984), the exposure of the brain to circulating gonadal steroids permanently influences a variety of morphological characteristics such as neuronal size, neuron number, dendritic branching, and the synaptic connectivity within different brain areas and in different species. Recent evidence has emerged demonstrating that the structural effects of gonadal steroids occur not only in the developing, but also in the adult CNS. In other words, in addition to the permanent effects that occur during a "critical period" of development, the structural composition of specific brain areas can be modified by, and is dependent on, the hormonal environment of the adult brain (DeVoogd, 1987; Arnold and Jordan, 1988; Gould et al., 1990).

Studies within two motor systems have contributed

Received December 4, 1990; June 19, 1991

Address reprint requests to Diana M. Gomez, Dept. of Anatomy and Cell Biology, Medical Science Bldg. II, University of Michigan, Ann Arbor, MI 48109-0616. 
the majority of the evidence correlating morphological plasticity with hormonal manipulations in the adult. These are the avian forebrain song system (Nottebohm, 1980; DeVoogd and Nottebohm, 1981; DeVoogd et al., 1985; Canady et al., 1988) and the rodent neuromuscular system (Kurz et al., 1986; Forger and Breedlove, 1987; Leedy et al., 1987; Matsumoto et al., 1988). The ventromedial nucleus and the arcuate nucleus of the hypothalamus are reproductive control areas that are also susceptible to the effects of gonadal steroids on neuronal structure in the adult brain (Cohen and Pfaff, 1981; Carrer and Aoki, 1982; Meisel and Pfaff, 1985; Nishizuka and Pfaff, 1989; Meisel and Luttrel, 1990). In addition, Witkin (1989) has demonstrated that the morphology of luteinizing hormone-releasing hormone neurons in the adult rodent is sensitive to circulating steroid hormones.

The present investigation has focused on the role of gonadal steroids within a sexually dimorphic chemosensory nucleus in the male Syrian hamster, the medial nucleus of the amygdala (Me). Steroid autoradiographic studies have demonstrated that $\mathrm{Me}$ is a target for both androgens and estrogens in this species (Krieger et al., 1976; Doherty and Sheridan, 1981). Because this nucleus transmits essential vomeronasal and olfactory information for the control of copulatory behavior (Lehman and Winans, 1982), this is an ideal system in which to study the effects of gonadal steroids on neural circuitry.

Although previous investigators have reported that neurons in Me are sensitive to perinatal manipulations of steroid hormones (Nishizuka and Arai, 1983a,b; Mizukami et al., 1983), little is known regarding the effects of these steroids on the structural organization of this nucleus in the adult. We hypothesized that gonadal hormones act in the adult hamster to modulate the dendritic morphology of these neurons. Based on the assumption that the dendritic arborization in $\mathrm{Me}$ is organized to receive and integrate the aforementioned chemosensory inputs to the molecular layer (direct vomeronasal input from the accessory olfactory bulb) and cellular layer (indirect olfactory input from cortical amygdala), it is possible that steroid hormones regulate chemosensory transmission through Me neurons by regulating their dendritic structure. Since previous lesion studies have reported that damage to the anterior, but not the posterior, part of Me eliminates mating behavior (Lehman and Winans, '82), we further hypothesized that gonadal hormones influence neuronal structure specifically in anterior $\mathrm{Me}$, to maintain the connections of these neurons with chemosensory inputs that control reproduction.

The first part of this research investigates the effect of castration on the dendritic morphology of Me neurons. In this analysis, Golgi-stained neurons from adult castrated and reproductively intact hamsters were compared in the anterior and posterior Me. Based on the results of this analysis, the following questions were addressed to further elucidate the mechanism by which steroids regulate the morphology of Me neurons. First, does treatment with gonadal steroids prevent the changes observed after castration? Second, does testosterone, one of its metabolites, or a combination of both metabolites mediate this effect? To address these questions, we quantitatively analyzed Golgi-stained neu- rons from reproductively intact males, castrated males, and castrated animals with one of four different hormonal treatments: testosterone, dihydrotestosterone, estradiol, or dihydrotestosterone plus estradiol. Mating behavior tests were conducted and flank glands were measured to verify that the silastic capsules were releasing hormones. Four different morphological characteristics of the neurons in Me were analyzed in this study: total dendritic length, highest dendritic branch, somal area, and spine density.

\section{METHODS \\ Animals}

Eighty-three adult male Syrian hamsters (Mesocricetus auratus), 8 weeks old, were obtained from Charles River (Wilmington, MA). Animals of this age are reproductively mature young adults. These animals were chosen because aging appears to compromise the ability of the neurons to be impregnated with the Golgi method (Millhouse, 1981). Animals were group housed in plastic cages and maintained on a $14 \mathrm{~h}$ light: $10 \mathrm{~h}$ dark illumination cycle with food and water available ad libitum. This lighting schedule maintains the gonads in an active reproductive state (Morin and Zucker, 1978).

\section{Experiment I: Design}

To test the hypothesis that androgens influence the dendritic morphology of the neurons in the medial nucleus, the dendrites of Golgi-impregnated neurons from the anterior and posterior parts of Me from the brains of seven adult castrated male hamsters were quantitatively analyzed and compared to the brains of four agematched intact hamsters. The experimental animals were castrated as young adults ( 8 weeks of age) and survived 12-13 weeks before their brains were processed. The 12-week survival period was chosen because male hamsters lose all components of mating behavior, with the exception of occasional mounts, 12 weeks after gonadectomy (Beach and Pauker, 1949; Morin and Zucker, 1978).

\section{Experiment II: Design}

Seven groups of animals were used in this study: reproductively intact male hamsters $(n=25)$, castrated animals implanted with an empty silastic capsule $(\mathrm{n}=14)$, castrates implanted with a single capsule filled with either testosterone $(T ; n=13)$, dihydrotestosterone (DHT; $n=13$ ), estradiol (E; $n=$ 13) or castrates implanted with two capsules, one with DHT and the other with estradiol $(n=8)$. All of these animals and 14 of the intact males survived 12 weeks after surgery. The brains of the remaining 11 intact males were processed at the beginning of the experiment, at 8 weeks of age, in order to provide a baseline for the morphology of the neurons at the beginning of the experiment. Because of this lengthy survival period and the need to provide a uniform level of hormone, chronic treatment of gonadal steroids was given with capsules rather than with daily injections. To ensure continuous release of hormones from the capsules throughout the entire 12 -week survival period, capsules were removed at 6 weeks and immediately replaced with new ones.

Data were collected from two replications of this 
study. In the second replication, mating behavior tests were performed and flank gland measurements were made at 6 and 12 weeks after castration. Adequate levels of circulating androgens are necessary to maintain the flank glands (Giegel et al., 1971). The rostralcaudal length of both right and left flank glands was measured. An average for the two glands was determined for each animal and the mean average length for each hormone treatment group was statistically compared to the mean for the 20-week control intact group (referred to throughout as "controls") using an ANOVA with a posthoc pairwise comparison (Scheffe). In addition, the size of the seminal vesicles was observed at the time of perfusion.

\section{Surgery}

Castration and hormone capsule placement were performed on anesthetized hamsters (sodium pentobarbitol, $10 \mathrm{mg}$ per $100 \mathrm{gm} \mathrm{BW}$ ). In both experiment I and II, the testis, epididymis, and distal vas deferens were removed through a midline scrotal incision when the animals were 8 weeks of age, and in experiment II, hormone capsules were implanted subcutaneously, superficial to the vertebral column, immediately after gonadectomy. The capsules were prepared as described by Powers et al. (1985), using silastic tubing (ID $1.57 \mathrm{~mm} /$ OD $3.18 \mathrm{~mm}$; Dow Corning, Midland, MI) filled with steroid hormones obtained from Sigma Chemical (St. Louis). The capsules were either empty or filled with crystalline testosterone $(\mathrm{T} ; 20 \mathrm{~mm})$, crystalline 5-alpha-androstan-17-beta-ol-3-one (DHT; $30 \mathrm{~mm}$ ), or 17 beta-estradiol dissolved in sesame oil ( $\mathrm{E} ; 25 \mathrm{mg} / \mathrm{ml}, 10$ $\mathrm{mm}$ ). All capsules were sealed at the ends with nylon fishing line and with Silicone adhesive. Capsules were immersed in $0.1 \mathrm{M}$ sodium phosphate buffer overnight to allow capsules to equilabrate prior to insertion (Powers et al., 1985).

\section{Behavioral Tests}

Animals in the second replication of the second study were tested for copulatory behavior immediately prior to capsule replacement and again prior to perfusion. Two mating behavior tests were given at both of these times, one 8 days and one 4 days prior to capsule replacement and, again, 8 days and 4 days prior to perfusion. Tests were conducted by placing a male hamster in a clear plastic cage with a sexually receptive female hamster. Adult, ovariectomized females were given subcutaneous injections of estradiol in sesame oil $(10 \mu \mathrm{g}) 48$ hours and 24 hours prior to testing and progesterone in sesame oil $(500 \mu \mathrm{g}) 4$ hours prior to testing to induce receptivity. The tests were run during the dark phase of the animals' light:dark cycle in a dimly illuminated room. Behavior was assessed by recording the occurrence of mounts, intromissions, and ejaculations in each of the experimental males. The testing period lasted 10 minutes or until the male had achieved two ejaculations, whichever occurred first.

\section{Histology}

Brains were prepared for histological analysis with a modification of the Ramon-Moliner method for Golgi impregnation of neurons (Greenough et al., 1977). At the end of week 12 postcastration, the animals were anesthetized and perfused transcardially with $150 \mathrm{ml}$ of $0.9 \%$ phosphate-buffered saline containing $0.1 \%$ sodium nitrite (for vasodilation) followed by $250 \mathrm{ml}$ of a solution containing $2.4 \%$ potassium dichromate, $6 \%$ chloral hydrate, $1.5 \%$ potassium chlorate, and $4 \%$ formaldehyde in distilled water. The brains were removed and immersed in the same fixative for 24 hours with replacement of fresh solution after 12 hours. They were then transferred to $3 \%$ potassium dichromate for 3 days and immersed in $1 \%$ silver nitrate for 8 days. All solutions were prepared and changed daily. Coronal sections $(120 \mu \mathrm{m})$ were cut on a freezing microtome, dehydrated, mounted, and coverslipped with Permount.

\section{Analysis of the Golgi-Impregnated Neurons}

Both left and right sides of each brain were used. Well-impregnated neurons were drawn using a camera lucida at a magnification of $500 \times$. The neurons from experiment I and the first replication of the second experiment were analyzed from these tracings using a digitizing bit pad linked to a Tectronics 4054 computerized measurement program. The data from the second replication of experiment II were analyzed without knowledge of the treatment groups and cells were measured directly using a digitizing bit pad linked to a Bioquant computerized measurement system ( $R$ \& $M$ Biometrics, Nashville, TN). Camera lucida drawings of the neurons in this replication were made for documentation.

Due to the variability of the number of cells in each brain that are fully stained using the Golgi technique, the number of neurons selected for analysis in each brain varied between animals. A neuron was selected for analysis only if it had a well-impregnated perikaryon and dendrites and if the branches were distinct and traceable. Cells from clusters of stained neurons with "tangled" dendrites were not selected. Unlike other brain areas, only a small number of neurons in Me were impregnated in each brain. Therefore in every brain, all the neurons in this region that met the two criteria above were studied. The mean number of neurons (and standard deviation) obtained for each animal was $4.92( \pm 3.49)$. The following measures for each neuron in both experiments were quantified from the section in which the cell body was localized: somal area, highest dendritic branch level (the number representing the highest level of branching for each neuron) and total dendritic length (the sum of the lengths of all the dendritic segments). The following measurements were also made on neurons in the second experiment: length of each dendritic segment at each branch level (primary, secondary, etc.), the number of dendrites at each branch level, and the number of spines on the distal $20 \mu \mathrm{m}$ of all terminal dendrites (dendrites that taper to a point). A record was made of which dendritic segments were cut off at the edge of the section.

Since the data in Experiment I met the requirements for parametric statistics of equality of variance and normality, the mean values of all three measures were statistically compared using a Student's t-test between neurons from intact and castrated animals either within anterior or posterior Me. Statistical analysis of the data in Experiment II was carried out with a oneway nested analysis of variance. Log transformations for the length data were used for statistical compari- 
son, although the figures and tables show actual mean length measures. Because Me contains both steroidconcentrating and nonsteroid-concentrating neurons, which are not distinguishable with Golgi impregnation techniques, it was assumed that the intra-animal variation would be as great as, or greater than, the interanimal variation of the data. The initial analysis was therefore performed comparing the mean values for all the neurons in a treatment group (i.e., a by neuron analysis) irrespective of animal. The appropriateness of this statistical approach in studies with large unavoidable intra-animal variation has been addressed by Leuba et al. (1989). Based on the hypothesis that each group is treated as an independent effect, a pairwise posthoc comparison (Scheffe) was also made between each of the experimental groups to the control intact group to identify in which of the experimental groups the changes were taking place. The percentage of neurons from each treatment group that had dendrites at each branch level was also determined and this measure was analyzed using Chi-square analysis.

\section{RESULTS \\ Experiment l: Changes in Neuronal Morphology After Castration}

Golgi-impregnated neurons $(n=109)$ from the anterior and posterior divisions of Me were analyzed and compared between castrated $(n=7$ animals; $n=60$ neurons) and reproductively intact ( $n=4$ animals; $n$ $=49$ neurons) hamsters. Neurons in both anterior and posterior parts of $\mathrm{Me}$ are uniformly small, with sparsely branched dendritic trees and ovoid, bipolar, or fusiform cell bodies. Dendrites of the neurons in posterior $\mathrm{Me}$ were often found extending into the narrow medial molecular layer immediately adjacent to the optic tract. Other dendrites were oriented either parallel or perpendicular to the fibers of the stria terminalis. In castrated animals, neurons from this region, but not from anterior Me, appeared to have fewer and shorter dendritic branches than those from intact animals (Fig. 1).

Quantitative comparison of the neurons from both anterior and posterior regions of $\mathrm{Me}$ revealed that in posterior $\mathrm{Me}$, castration resulted in a decrease in the number of cells that had distal dendritic branches. Contrary to our original hypothesis, no significant differences between the neurons from intact and castrate brains were observed in anterior $\mathrm{Me}$. These results suggest that castration-induced changes in the morphology of the anterior Me neurons are not the mechanism underlying the loss of mating behavior following gonadectomy. However, these findings are consistent with the observation that steroid accumulating neurons in $\mathrm{Me}$ are found primarily in the posterior part of this nucleus (Krieger et al., 1976; Doherty and Sheridan, 1981; Newman et al., 1991). In posterior Me, significant differences in the mean somal area $(\mathrm{t}=3.59, \mathrm{df}=$ $59, P<0.001)$ and the mean highest dendritic branch level were observed between the intact group and the castrated group in posterior $\mathrm{Me}(\mathrm{t}=2.06, \mathrm{df}=59, P<$ 0.05 ). These results are summarized in Figure 2.

Analysis of the percentage of neurons that had dendritic branches at each branch level (Table 1) suggested that these changes in dendritic branching were taking place at the tertiary branch level. To determine whether length changes were taking place at this branch level, the mean length of third-order branches for individual neurons with third-order branches in anterior and posterior Me was also compared. No statistical differences, however, were observed in the length of third-order branches between intact and castrated animals within either the anterior or posterior regions.

Castration produced a $23 \%$ decrease in the mean total dendritic length in neurons of posterior Me (Fig. 2). Although these data indicate a tendency for neurons in posterior Me from intact males to have a greater overall total dendritic length, this difference was not significant. No differences were observed between the two groups of animals in the anterior region.

To determine whether the data were biased due to a greater selection of neurons in posterior Me with dendrites that had been cut, the depth of the neuron within the section was determined for the four groups (anterior Me-intact, posterior Me-intact, anterior Me-castrate, posterior Me-castrate). Neurons in each group were found to be evenly distributed throughout the depth of the section.

\section{Experiment II: Influence of Gonadal Hormones on Neuronal Morphology}

\section{Behavioral tests}

Data from the behavioral tests confirmed the effectiveness of the steroid containing capsules for delivery of hormones to the bloodstream. The results of the four behavioral tests for all the animals ( 2 tests at 6 weeks and 2 tests at 12 weeks postcastration) are combined and summarized in Figure 3. Consistent with previous studies, hamsters treated with $\mathrm{DH}^{\mathrm{T}}$, DHT $+\mathrm{E}$, and T retained the entire copulatory repertoire of mounts, intromissions, and ejaculations, as did the reproductively intact animals (Whalen and DeBold, 1974; Payne and Bennett, 1976; Powers et al., 1985). Animals in the E-treated group continued to mount and showed occasional intromissions, but these males did not ejaculate. They did, however, show a high level of general activity during the tests that differed from the activity of castrated animals. Castrated animals, as expected, demonstrated a decrease in all three measures of reproductive behavior.

Flank glands

Analysis of the flank glands also demonstrated release of hormones from the capsules. The average lengths of both flank glands for each animal were measured and an average for each animal was determined (Table 2). Animals treated with T had slightly larger flank glands than the control group, but this difference was not statistically significant. Animals given either DHT or DHT + E had significantly larger flank glands than control intacts $(\mathrm{F}(1,55)=27.2,15.6, P<0.001)$, which suggests that animals were receiving supraphysiological levels of androgens. Estradiol-treated and castrated animals had significantly reduced flank gland size compared to control intacts $(F(1,55)=184.5$, 186.4, $P<0.0001$ ). Flank glands for 8 -week-old intacts had not reached the size of the 20 -week-old, intact controls $(\mathrm{F}(1,55)=30.6, P<0.001)$.

\section{Seminal vesicles}

Seminal vesicles were assessed grossly at the time of perfusion. Seminal vesicles from intact, T, DHT and 


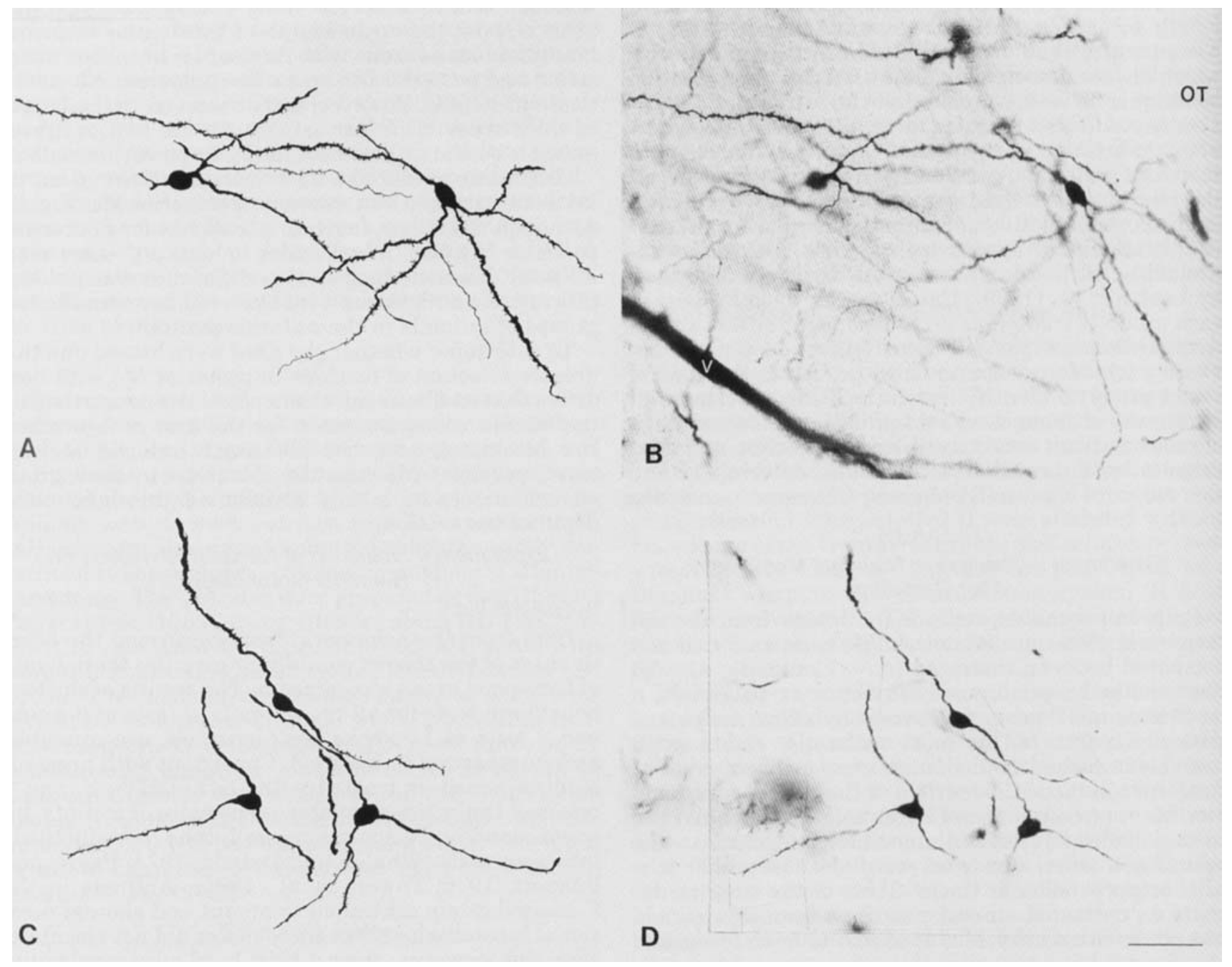

Fig. 1. Camera lucida tracings $(\mathbf{A}, \mathbf{C})$ and corresponding photomicrographs $(\mathbf{B}, \mathbf{D})$ of neurons in posterior Me from an intact (A, B) and castrated (C, D) animal. Note the highest level of branching for the neurons in the intact animal is at the tertiary level ( $\mathrm{HDB}=3$ ), whereas the HDB level for the most branched neuron in the castrated animal is the secondary level ( $\mathrm{HDB}=2)$. V, vessel; OT, optic tract. Bar $=50 \mu \mathrm{m}$.

$\mathrm{DHT}+\mathrm{E}$ groups were large. In the castrated and Etreated groups, the glandular tissue was difficult to detect in the fatty stroma surrounding the glands.

\section{Golgi neurons}

A total of 328-Golgi impregnated neurons were quantitatively analyzed for three morphological parameters (somal area, highest level of dendritic branching, and total dendritic length). The number of spines on the distal $20 \mu \mathrm{m}$ were counted on a total of 279 terminal dendrites. The pattern of differences between treatment groups on all four of these neuronal parameters was similar (Fig. 4). In each parameter, the measures for neurons in castrated and DHT-treated males were below those of control intacts and the testosterone-treated males were equivalent to the control intacts. The nested ANOVA analysis by neuron across treatment groups with post-hoc pairwise comparisons
(Scheffe) between intacts and each experimental group revealed a significant decrease in the somal area of the castrated and DHT-treated males compared to the control intact group (Fig. 4; Castrate: $\mathrm{F}(6,321)=13.11 P$ $<0.0001$; DHT: $\mathrm{F}(6,321)=23.5 P<0.0001)$. Examples of representative somal areas from three different groups are shown in Figure 5. Each neuron was assigned a value that represented the highest dendritic branch (HDB; first, second, third, etc.). The highest dendritic branch for each neuron was determined, the mean for each animal within a group was determined, and the means between treatment group were compared (Fig. 4). The highest level of dendritic branching was also significantly reduced in these two treatment groups (Castrate: $\mathrm{F}(6,322)=5.11 P=0.02$; DHT: $\mathrm{F}(6,322)=4.78 P=0.03)$. The remaining groups were not different than controls.

The percentage of neurons in each of the experimen- 

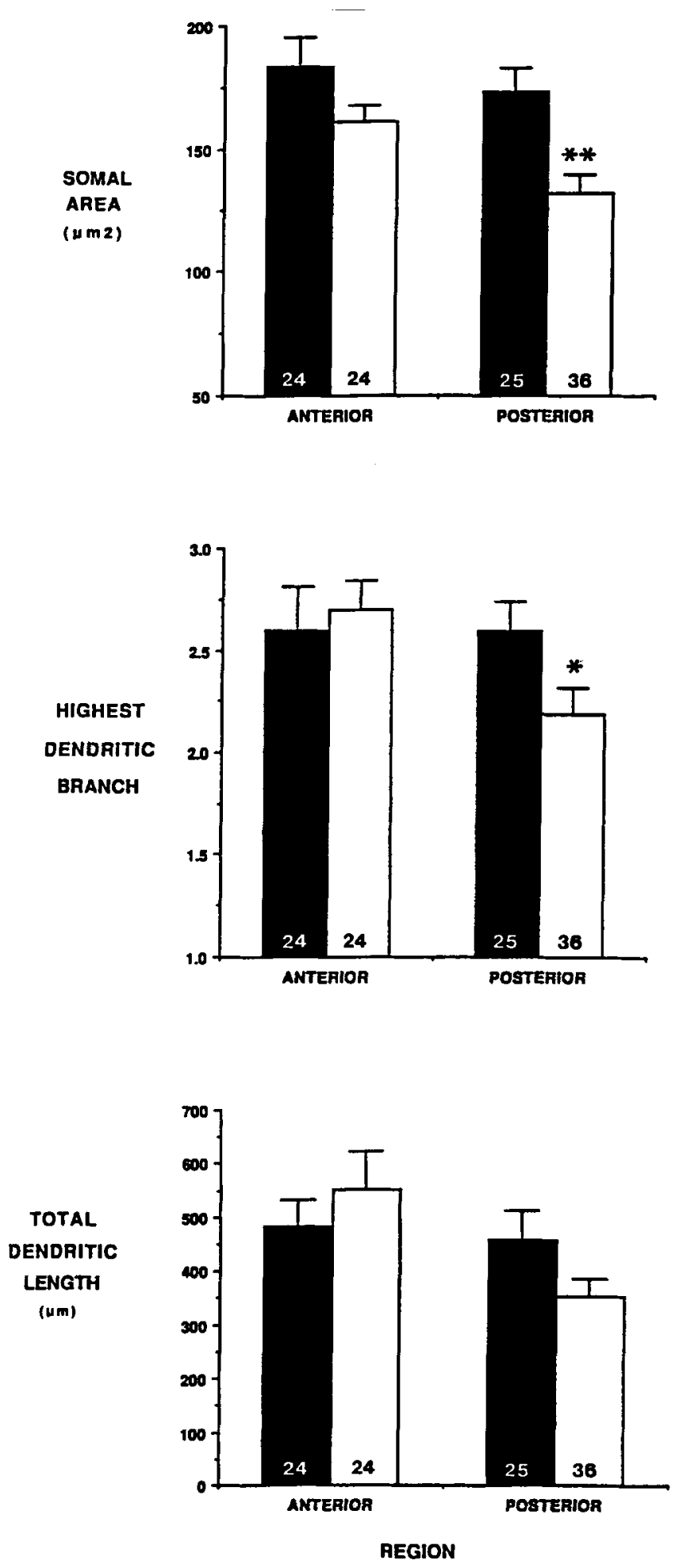

Fig. 2. Mean somal area, highest dendritic branch, and total dendritic length ( \pm S.E.M.) for neurons in castrated (open bars) and agematched intact hamsters (closed bars) in anterior and posterior Me. The numbers in the bars represent the total number of neurons analyzed for each group. ${ }^{*} P<0.05 ; * * P<0.001$.
TABLE 1. Experiment I: Percentage of neurons with dendrites at each branch level

\begin{tabular}{llrrrr}
\hline & & 1st & 2nd & 3rd & 4th \\
\hline $\begin{array}{l}\text { A. Anterior } \\
\quad \text { Intact }\end{array}$ & $(\mathrm{n}=24)^{1}$ & $100 \%$ & $83 \%$ & $54 \%$ & $21 \%$ \\
$\quad$ Castrate & $(\mathrm{n}=24)$ & 100 & 88 & 63 & 21 \\
$\begin{array}{l}\text { B. Posterior } \\
\quad\end{array}$ & & & & \\
$\quad$ Intact & $(\mathrm{n}=25)$ & 100 & 96 & 56 & 1 \\
Castrate & $(\mathrm{n}=36)$ & 100 & 83 & $31^{*}$ & 0 \\
\hline
\end{tabular}

${ }^{1} \mathrm{n}=$ numbers of neurons.

$* P<0.05$.

tal groups that had dendritic branches at a given level (primary, secondary, etc.) and the mean number of branches per neuron at that level are shown in Table 3. Again, as in Experiment I, the percentage of neurons that had third-order dendritic branches was reduced in castrated and, here, in DHT-treated animals compared to control intacts (Castrate: $P=0.02$, DHT: $P=0.03$ ). A tendency for a decrease in the percentage of neurons that had secondary branches in these same groups was noted (castrate: $86 \%$, DHT: $84 \%$ ), but these percentages were not significantly different from those of the control group. The remaining treatment groups were not different from the control intacts. In addition, there were no significant differences observed in the mean number of dendrites at any of the branch levels between any of the treatment groups.

The mean values for total dendritic length for the groups are shown in Figure 4. Neurons in castrated males had slightly shorter dendritic trees, but this difference was not statistically significant. DHT-treated animals, in contrast, had neurons with significantly reduced total dendritic lengths compared to intacts $[\mathrm{F}(6,304)=5.57, P=0.02]$. Again, the remaining experimental groups were not significantly different from controls. To determine if there were selective changes in the lengths of specific dendritic segments that might have been masked in the calculation of total dendritic length and to determine where these selective changes were taking place in the neurons of castrate and DHTtreated animals, the average length of the dendrites at the secondary and tertiary levels were analyzed separately. For this analysis, all the dendrites at these two segment levels were subdivided into two subgroups: branched and terminating (tapering to a point distally). Dendrites that were cut off at the edge of the section were noted and eliminated from the analysis. The average lengths of the secondary and tertiary dendrites were statistically compared (Table 4). Although no significant differences were observed in the lengths of either the branched or terminal dendrites between these groups, the numbers of branched and terminal dendrites available for analysis at the secondary and tertiary branch level reflected the previously determined difference in the numbers of these branches.

The mean number of spines found on the distal 20 $\mu \mathrm{m}$ of all terminal dendrites in each experimental group is shown in Figure 4 . When the means for each group were statistically compared to the control intact group, once again, neurons from castrates demonstrated a slight decrease that was not significant, whereas those from animals treated with DHT had 


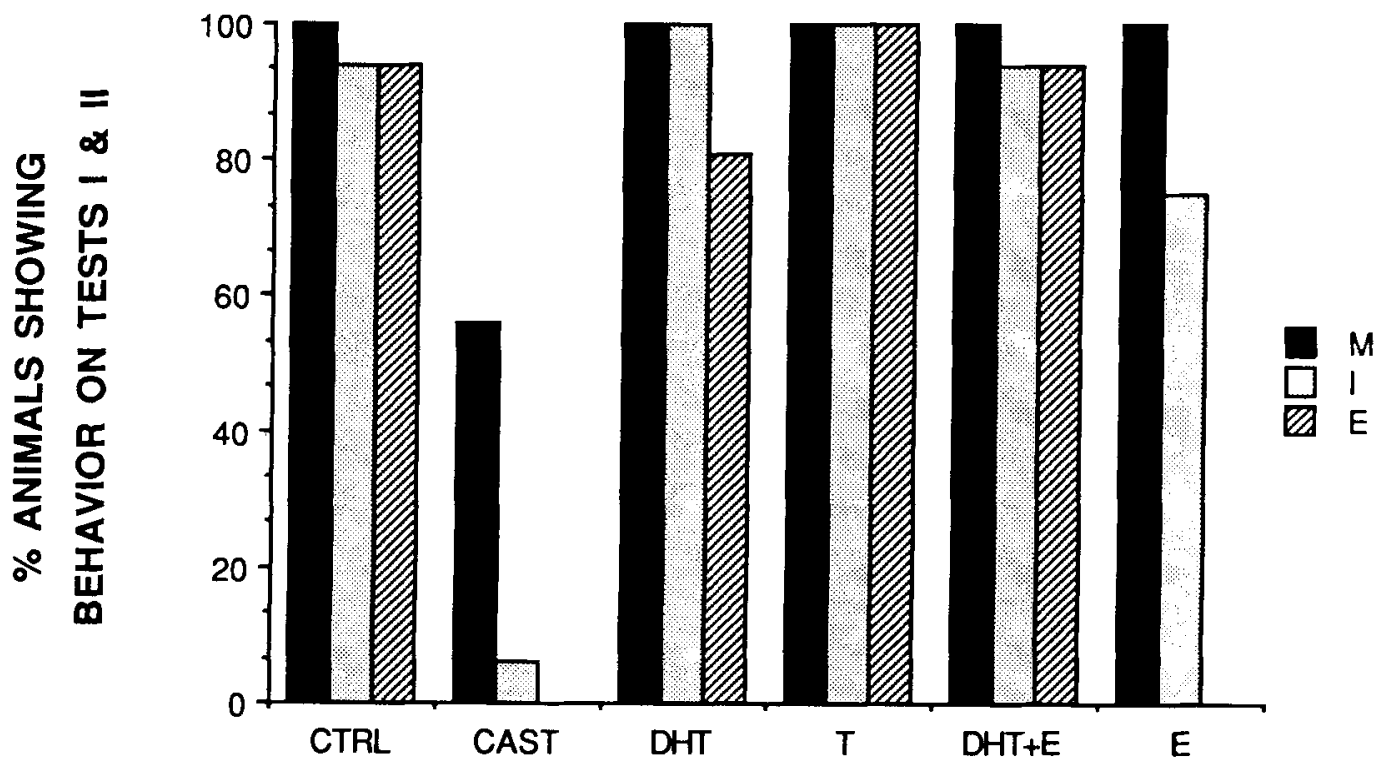

\section{GROUPS}

Fig. 3. The percentage of animals from each of the treatment groups which demonstrated mounts (M), intromissions (I), and ejaculations (E) are shown. Data from the behavioral tests at 6 and 12 weeks after castration are combined. 20-week control intacts (CTRL); castrate (CAST); dihydrotestosterone (DHT); testosterone (T); estradiol (E).

TABLE 2. Average lengths of flank glands

\begin{tabular}{lcc}
\hline & & $\begin{array}{c}\text { Average length }(\mathrm{mm}) \\
+ \text { S.E.M. }\end{array}$ \\
\hline CTRL intact & $(\mathrm{n}=9)$ & $7.85 \pm 0.41$ \\
8 week intact & $(\mathrm{n}=8)$ & $5.81 \pm 0.29^{* *}$ \\
Castrate & $(\mathrm{n}=8)$ & $2.82 \pm 0.20^{* *}$ \\
DHT & $(\mathrm{n}=8)$ & $9.53 \pm 0.35^{* *}$ \\
T & $(\mathrm{n}=8)$ & $8.30 \pm 0.34$ \\
DHT $+\mathrm{E}$ & $(\mathrm{n}=8)$ & $9.27 \pm 0.31^{* *}$ \\
E & $(\mathrm{n}=8)$ & $2.77 \pm 0.26^{* *}$ \\
\hline
\end{tabular}

$* * P<0.001$.

fewer spines on the terminating dendrites than control intacts [DHT: $F(6,272)=5.32 P=0.02$ ]. Most, although not all, of the terminal dendrites of neurons in DHT-treated animals were devoid of spines (Fig. 6).

Since the findings reported above indicated changes in the castrated and DHT-treated males, the depth of the neuron within the section was determined for all the neurons in the control intact, castrate and DHTtreated animals. These neurons were found to be distributed evenly throughout the section in all these groups. Thus the data for neurons from DHT-treated or castrated animals were not biased due to a disproportionate selection of neurons with dendrites that were likely to have been cut.

Finally, the 8-week-old intact males were not significantly different from the 20 -week-old (control) males on any measure.

\section{DISCUSSION}

Previous studies have shown evidence of gonadal hormone dependent plasticity within the adult central nervous system (DeVoogd, 1987; Arnold and Jordan, 1988). Both light and electron microscopic investigations have revealed structural characteristics that are altered in response to hormonal manipulations in areas of the central nervous system containing steroid-accumulating neurons. In the adult avian song system, dendritic length, dendritic number, nuclear volume, number of spines, number of synapses, and synaptic size are modified by changes in testosterone levels (DeVoogd and Nottebohm, 1981; DeVoogd et al., 1985; Canady et al., 1988). Similar changes have been reported in the adult rodent bulbocavernosus nucleus of the spinal cord, not only after castration and testosterone replacement studies (Kurz et al., 1986; Leedy et al., 1987; Matsumoto et al., 1988), but also throughout the seasonal breeding cycle (Forger and Breedlove, 1987). Studies of a third adult system, the female rodent lordosis pathway, have revealed steroid hormone effects on ultrastructural features within the hypothalamus, where changes in synaptic connectivity and intraneuronal organelles occurred after estradiol treatment (Cohen and Pfaff, 1981; Carrer and Aoki, 1982; Cohen et al., 1984; Meisel and Pfaff, 1985). Recent studies have reported changes in the number of spines (Gould et al., 1990) and dendritic length (Meisel and Luttrell, 1990) in the ventromedial nucleus of the hypothalamus after ovariectomy and estradiol replacement.

In the present study, somal area and third-order dendritic branches were altered in neurons of the posterior medial nucleus of the amygdala (Me) after long-term castration. Neurons in anterior Me, in contrast, did not show corresponding changes in response to castration and therefore served as an internal control for nonspecific effects on neurons of the central nervous system. 

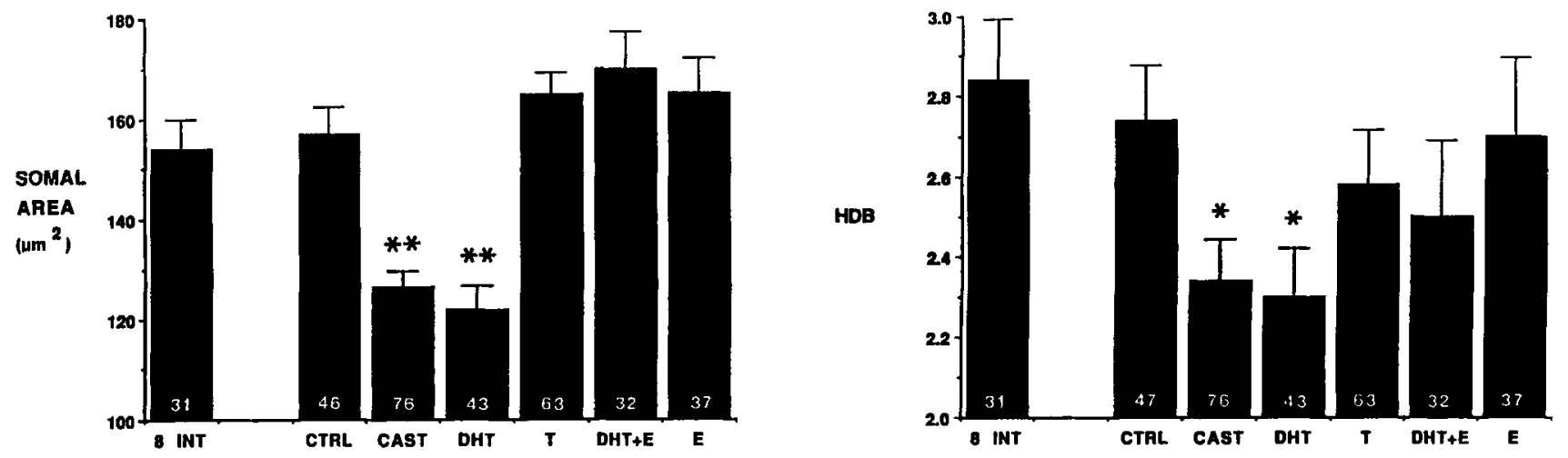

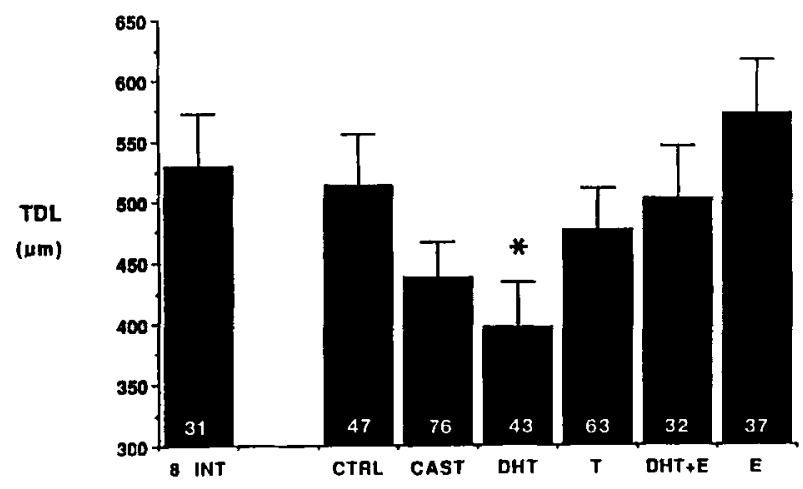

Fig. 4. Mean somal area, highest dendritic branch (HDB), total dendritic length (TDL) and spine density ( \pm S.E.M.) for 8 week intacts ( 8 INT), control or 20 week intacts (CTRL), castrates (CAST), dihydrotestosterone-(DHT), testosterone-(T), dihydrotestosterone plus es-

These changes were derived from analysis of a total of 437 neurons in 83 animals for experiments I and II. Unlike the aforementioned earlier studies, no changes were observed in dendritic length of the neurons in $\mathrm{Me}$ in response to castration. Overall, however, the results reported here are quite similar to those recently observed in the sexually dimorphic nucleus of the bulbocavernosus muscle in the spinal cord (Sasaki and Arnold, 1991). These authors reported significant changes in somal area of the neurons in this nucleus. They also found subtle changes in dendritic morphology, including decreased length of third-order dendritic segments in a detailed study of 25 HRP-filled neurons from 22 animals. In the current study, the percentage of neurons with third-order dendritic branches was reduced in castrated males and this was observed in two separate experiments (Tables 1,3 ). Where third-order branches were present, they were not significantly reduced in length (Table 4). In addition, Sasaki and Arnold (1991) reported that testosterone treatment prevented the changes observed after castration. In the present study, testosterone, estradiol, and dihydrotestosterone plus estradiol similarly maintained somal and dendritic structure. In animals that were castrated and treated with dihydrotestosterone, however, somal area, the presence of third-order branch segments, total dendritic length and spine denisty were all reduced.

Analysis of the data in the first experiment comparing treatment groups in the two regions of Me demonstrated a high degree of intra-animal variability. Based on this, we chose to analyze the data in both experiments by comparing groups of neurons since comparisons between groups of animals ignores the inherent variability in the mixed population of steroidconcentrating and nonsteroid-concentrating cells that were indiscriminantly impregnated with the Golgi technique. In spite of this unavoidable mixing, significant differences in the dendritic branching pattern were demonstrated by comparing the proportion of the total population of neurons in castrate versus intact groups that displayed tertiary dendrites. Thus the differences demonstrated here are most likely a conservative estimate of the changes occuring in hormone accumulating cells following castration.

Biochemical studies have shown that testosterone is enzymatically converted to estradiol by aromatase or into dihydrotestosterone by 5 -alpha reductase in the brain (Martini, 1978) and that both of these enzymes are found in the medial nucleus of the amygdala (Selmanoff et al., 1977; Roselli et al., 1985; Shinoda et al., 1989). In the experiments reported here, the neurons in 

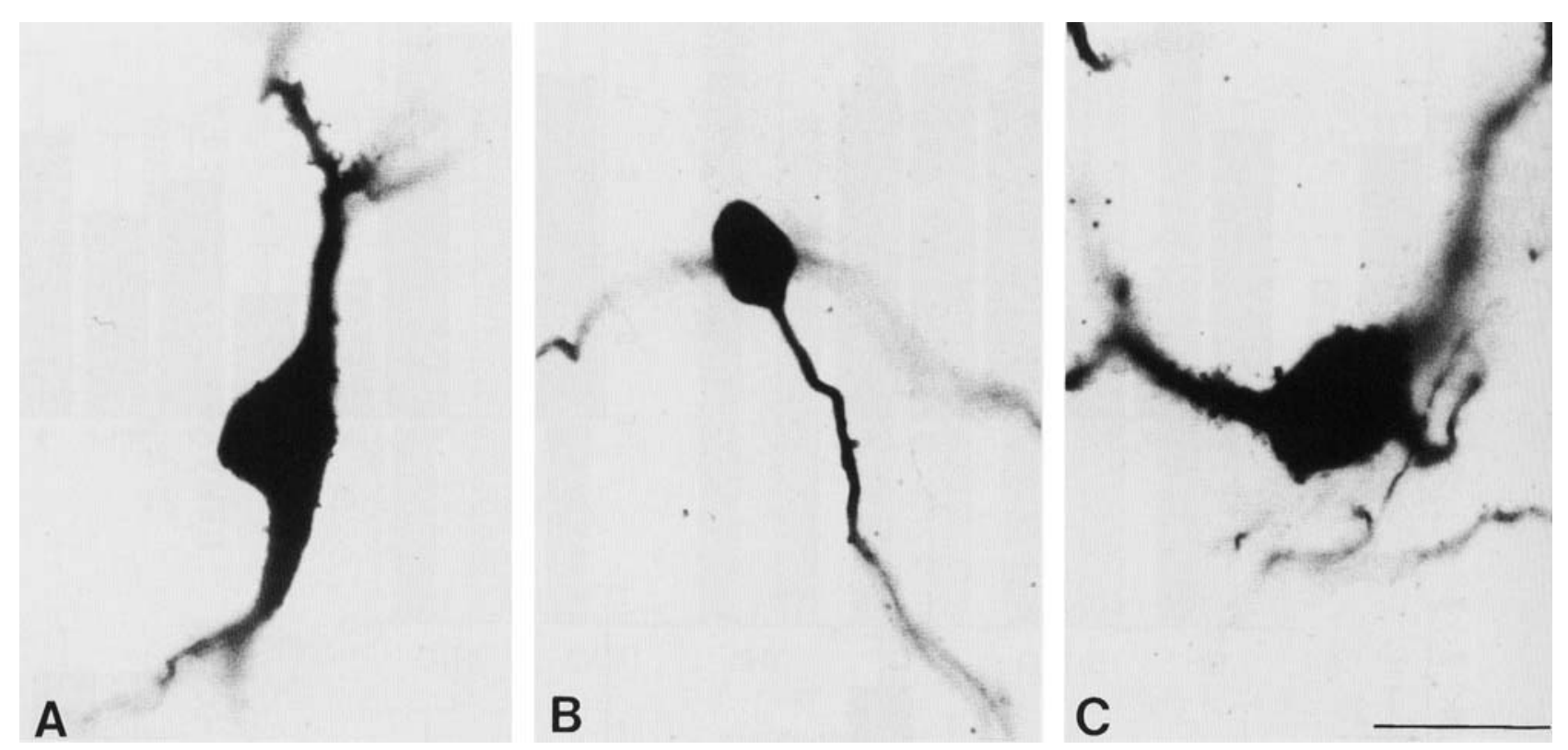

Fig. 5. Representative photomicrographs of cell bodies from a neuron taken from the brain of a control intact (A), a DHT-treated (B), and E-treated (C) animal. The presence of spine appendages were noted in several E-treated neurons. Bar $=20 \mu \mathrm{m}$.

TABLE 3. Experiment II: Percent of neurons with dendrites at each branch level and average numbers of branches at each level

\begin{tabular}{|c|c|c|c|c|c|c|c|c|c|c|c|}
\hline \multirow[b]{3}{*}{ Group } & & \multicolumn{10}{|c|}{ Dendritic branch level } \\
\hline & & \multicolumn{2}{|r|}{$1 \mathrm{st}$} & \multicolumn{2}{|r|}{ 2nd } & \multicolumn{2}{|r|}{ 3rd } & \multicolumn{2}{|r|}{4 th } & \multicolumn{2}{|r|}{5 th } \\
\hline & & $\%$ & Ave. \# & $\%$ & Ave. \# & $\%$ & Ave. \# & $\%$ & Ave. \# & $\%$ & Ave. \# \\
\hline CTRL intact & $(\mathrm{n}=47)^{1}$ & 100 & $2.3 \pm .11$ & 94 & $3.1 \pm .17$ & 60 & $3.2 \pm .29$ & 15 & $3.1 \pm .59$ & 6 & $2.3 \pm .33$ \\
\hline 8 week intact & $(\mathrm{n}=31)$ & 100 & $2.4 \pm .13$ & 97 & $3.5 \pm .21$ & 65 & $3.1 \pm .30$ & 19 & $2.0 \pm .00$ & 3 & $2.0 \pm .00$ \\
\hline Castrate & $(\mathrm{n}=76)$ & 100 & $2.4 \pm .07$ & 86 & $3.0 \pm .16$ & $38^{*}$ & $2.7 \pm .23$ & 8 & $2.7 \pm .42$ & 3 & $3.0 \pm .33$ \\
\hline DHT & $(n=43)$ & 100 & $2.3 \pm .10$ & 84 & $2.9 \pm .23$ & $37^{*}$ & $2.6 \pm .51$ & 7 & $2.7 \pm .66$ & 2 & $4.0 \pm .00$ \\
\hline $\mathrm{T}$ & $(\mathrm{n}=63)$ & 100 & $2.2 \pm .08$ & 90 & $3.0 \pm .16$ & 48 & $2.6 \pm .23$ & 18 & $2.4 \pm .24$ & 3 & $3.0 \pm 1.0$ \\
\hline $\mathbf{D H T}+\mathbf{E}$ & $(\mathbf{n}=32)$ & 100 & $2.2 \pm .09$ & 88 & $3.1 \pm .22$ & 41 & $2.6 \pm .35$ & 13 & $2.5 \pm .50$ & 9 & $2.0 \pm .00$ \\
\hline & $(\mathbf{n}=37)$ & 100 & $2.4 \pm .10$ & 89 & $3.4 \pm .24$ & 51 & $2.5 \pm .25$ & 19 & $2.3 \pm .29$ & 5 & $3.0 \pm 1.0$ \\
\hline
\end{tabular}

${ }^{1} \mathrm{n}=$ numbers of neurons.

$* P<0.05$.

Me of the castrated male were as sensitive to the effects of estradiol as to those of testosterone, whereas dihydrotestosterone appeared to be ineffective. Thus in this system, the two androgens, testosterone and dihydrotestosterone, have different effects on neuronal morphology. These in vivo actions in the hamster resemble those in cultures of the hypothalamus in newborn mice (Torand-Allerand, 1984), where estradiol significantly enhanced neurite outgrowth but dihydrotestosterone was ineffective.

In addition to testing the effects of the metabolites of testosterone, the effect of postpubertal hormone exposure was also addressed in this study. It is possible that gonadal steroids may, in fact, be promoting the growth of the dendrites after puberty. If this were the case, castration at 8 weeks of age in these animals could have simply interrupted their normal development rather than causing a change in dendritic branching. Therefore, we compared the dendrites and somal area of intacts at the end of puberty ( 8 weeks, the age at which the experimental animals were castrated) to the experimental and control groups that survived for an additional 12 weeks. We predicted that the quantitative neuronal characteristics of these 8-week males might be equivalent to the castrates or intermediate between the castrated and control intact groups. However, none of the measures of structural characteristics supported this prediction. Thus these results indicate that the neurons in the 8-week-old males are morphologically mature. There is no indication that gonadal steroids after puberty stimulate the growth of dendritic segments. However, a study including prepubertal, pubertal, and postpubertal animals would be of interest to further understand the physiological significance of the growth promoting properties of circulating gonadal steroids.

Gonadal steroids are known to influence the physiology as well as the structure of neurons in the adult 
TABLE 4. Numbers and lengths of $2^{\circ}$ and $3^{\circ}$ dendritic branches

\begin{tabular}{lrrrr}
\hline & \multicolumn{2}{c}{$2^{\circ}$} & \multicolumn{1}{c}{$3^{\circ}$} \\
\cline { 2 - 5 } $\begin{array}{l}\text { Group and } \\
\text { branch type }\end{array}$ & $\mathrm{n}$ & $\begin{array}{c}\text { Length } \\
(\mu \mathrm{m}) \pm \mathrm{S} . \mathrm{E} .\end{array}$ & $\mathrm{n}$ & $\begin{array}{r}\text { Length } \\
(\mu \mathrm{m}) \pm \mathrm{S} . \mathrm{E} .\end{array}$ \\
\hline CTRL intact & & & & \\
$\quad$ Branched & 42 & $56.7 \pm 11.2$ & 13 & $51.3 \pm 12.9$ \\
$\quad \begin{array}{l}\text { Terminal } \\
\text { Castrate }\end{array}$ & 11 & $93.8 \pm 20.4$ & 23 & $129.9 \pm 22.6$ \\
$\quad$ Branched & 39 & $59.9 \pm 9.9$ & 8 & $67.6 \pm 19.7$ \\
$\quad$ Terminal & 36 & $114.1 \pm 11.7$ & 13 & $70.2 \pm 8.6$ \\
DHT & & & & \\
$\quad$ Branched & 22 & $52.3 \pm 14.0$ & 4 & $35.0 \pm 10.8$ \\
Terminal & 6 & $94.7 \pm 20.8$ & 3 & $36.9 \pm 11.0$ \\
\hline
\end{tabular}
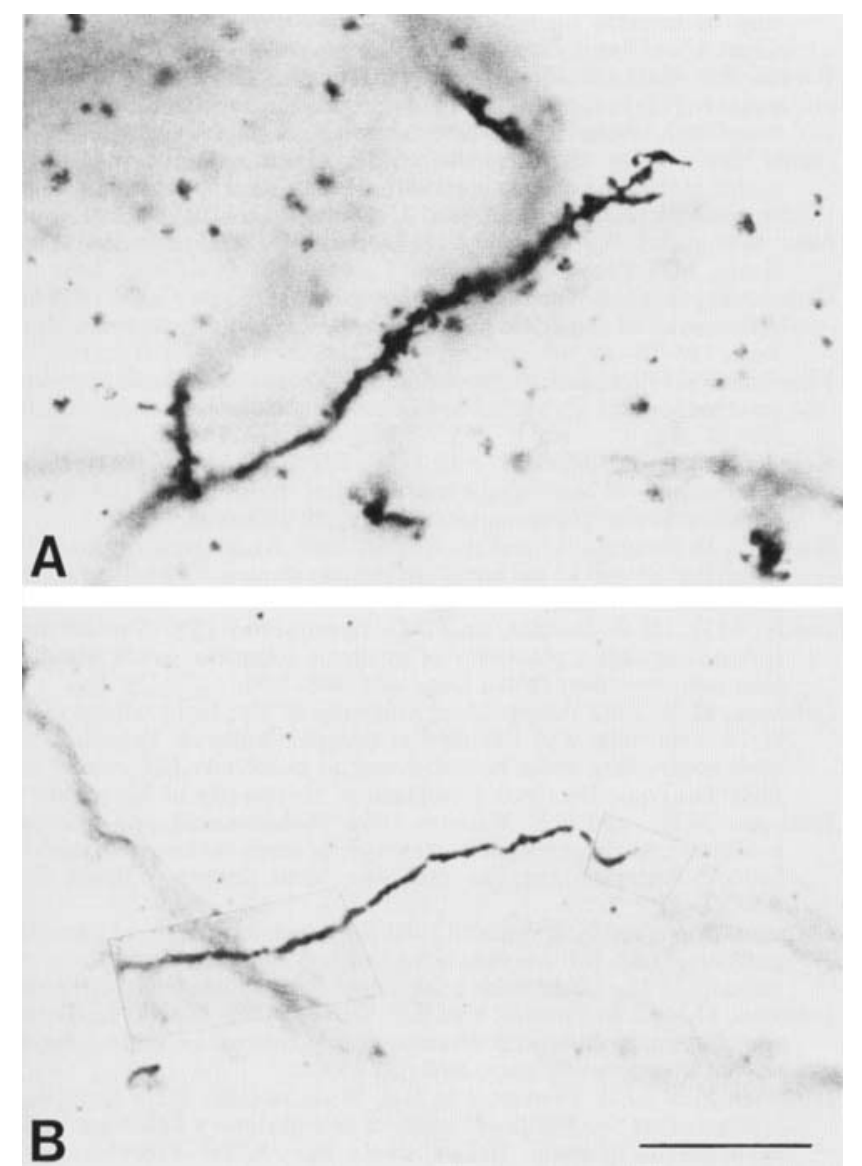

Fig. 6. These photomicrographs consist of a spinous terminal dendrite from an E-treated (A) and an aspinous terminal dendrite from a DHT-treated (B) animal. Bar $=20 \mu \mathrm{m}$.

central nervous system. They have been observed to influence the plasma membrane responsiveness of neurons in the arcuate nucleus of the hypothalamus and cerebral cortex (Olmos et al., 1987; Garcia-Segura et al., 1986). In Me, estradiol has been shown to have a stimulatory effect on the membrane of the neurons (Kendrick and Drewitt, 1980; Nabekura et al., 1986; Scheiss et al., 1988), whereas dihydrotestosterone appeared to have no effect (Kendrick and Drewitt, 1980).
Although the mechanisms underlying these changes are not understood, it is clear that in some cases shortterm membrane effects of the hormones are important (Nabekura et al., 1986; Scheiss et al., 1988).

Long-term effects of gonadal hormones, in contrast, appear to be mediated through the genome. Testosterone, or its metabolite estradiol, presumably binds to a receptor complex, which then stimulates the protein synthetic machinery of the cell. Increases, after estrogen treatment, in specific cytoplasmic organelles, including rough endoplasmic reticulum, polyribosomes and Golgi apparatus, suggest a stimulation of the protein synthetic capacity of the cell (Carrer and Aoki, 1982; Meisel and Pfaff, 1985). It is likely that these neurons may also be stimulated to increase production of cytoskeletal elements or membranous components that contribute to the maintenance of their dendritic structure.

It is well documented that gonadal hormones act in the central nervous system to stimulate reproductive behavior. In castrated male hamsters, copulatory behavior can be maintained not only with exogenous, systemic testosterone replacement, but also with either one of testosterone's metabolites, dihydrotestosterone (Whalen and DeBold, 1974; Payne and Bennett, 1976; Powers and Bergondy, 1983; Powers et al., 1985), or estradiol (DeBold and Clemens, 1978; Powers et al., 1985). Our behavioral results are in agreement with these previous studies. Animals treated with estradiol showed mounting and intromission behavior throughout the testing period, although they were unable to achieve ejaculations, presumably because estradiol alone was not able to support the structure and function of the genital tissues and glands. Analysis of flank glands and seminal vesicles revealed atrophy in these estradiol-treated males, although neuronal structure in posterior Me was not altered in any of the parameters measured.

In contrast, animals given dihydrotestosterone alone maintained mounts, intromissions, and ejaculations, in spite of reductions in somal area and alterations in the dendritic segments of neurons in posterior $\mathrm{Me}$, alterations that were equivalent to the neuronal changes in castrated males. Thus dihydrotestosterone may be stimulating or maintaining the morphology of neurons in other areas of the mating behavior pathway such as the bed nucleus of the stria terminalis or the medial preoptic area (Powers et al., 1987) to positively influence mating behavior. The morphological changes in posterior $\mathrm{Me}$ and continuing behavior of the dihydrotestosterone treated males suggest that maintenance of the neuronal structure of the cells in this posterior area is not necessary for reproductive behavior to occur, and this conclusion is consistent with previous lesion studies in which damage to posterior $\mathrm{Me}$ alone did not eliminate mating behavior in the hamster (Lehman et al., 1980). However, damage to the stria terminalis or damage to posterior $\mathrm{Me}$ alone did disrupt the normal temporal pattern of copulatory behavior and resulted in delayed ejaculations (Lehman et al., 1983).

It is possible, therefore, that in the intact male, a balance of hormonal effects, including dihydrotestosterone inhibition of the cells in posterior Me, is actually timing the pattern of this important behavior. In the normal animal, the modulatory effect of dihy- 
drotestosterone would reflect physiological inhibition of the neurons in posterior Me. What may be seen in the males treated with dihydrotesterone in this study is, therefore, the morphological result of long-term treatment with supraphysiological levels of this steroid hormone. Since behavioral observations in the present study were performed simply to verify the effectiveness of the implanted silastic capsules, they did not include the recording of temporal data necessary to test the prediction that the dihydrotestosterone-treated animals would show behavioral changes like those with $\mathrm{MeP}$ and stria terminalis lesions observed by Lehman et al. (1983).

In summary, the results reported here suggest that the accumulation of gonadal steroids in neurons of posterior $\mathrm{Me}$ influences neuronal structure. Neurons from animals that received testosterone, estradiol, or both dihydrotestosterone and estradiol were not different from those in the control intact males, whereas in dihydrotestosterone-treated males, the neurons of posterior Me were similar in size and dendritic branching to the posterior Me cells in long-term castrated males. However, all hormone-treated animals displayed sexual behavior. Taken together, these morphological and behavioral results are consistent with data from previous lesion studies and with the hypothesis that circulating testosterone may be actively taken up by $\mathrm{Me}$ neurons and enzymatically converted to both metabolites for the normal regulation of structure and function. We have not, however, ruled out the possibility that the changes observed in this study may be secondary to steroid-mediated changes elsewhere in the brain, which in turn may result in altered inputs to Me. Further studies will be necessary to define the relationship between this hormonally mediated plasticity and mechanisms for the control of mating behavior in the adult male Syrian hamster.

\section{ACKNOWLEDGMENTS}

We thank R.K. Brabec and L. Dudus of the Reproductive Sciences Morphology Core for their technical assistance (supported by 1-P30-HD-18258). We also thank K. Welsh and K. Guier for their statistical consultation, and we appreciate Dr. R. Meisel's helpful comments on a previous version of this manuscript. This research was supported by NIH grant NS20629 to S.W.N.

\section{LITERATURE CITED}

Arnold, A.P., and S.M. Breedlove 1985 Organizational and activational effects of sex steroids on brain and behavior: A reanalysis. Horm. Behav., 19:469-498.

Arnold, A.P., and C.L. Jordan 1988 Hormonal organization of neural circuits. In: Frontiers in Neuroendocrinology, Vol. 10. Raven Press, New York.

Beach, F, and R. Paulker 1949 Effects of castration and subsequent androgen administration upon mating behavior in the male hamster (Cricetus auratus). Endocrinology, 45:211-221.

Canady, R.A., G.D. Burd, T.J. DeVoogd, and F. Nottebohm 1988 Effect of testosterone on input received by an identified neuron type of the canary song system: A golgi/electron microscopy/degeneration study. J. Neurosci., 8:3770-3784.

Carrer, H.F., and A. Aoki 1982 Ultrastructural changes in the hypothalamic ventromedial nucleus of ovariectomized rats after estrogen treatment. Brain Res., 240:221-233.

Cohen, R., and D.W. Pfaff 1981 Ultrastructure of neurons in the ventromedial nucleus of the hypothalamus in ovariectomized rats with or without estrogen treatment. Cell Tissue Res., 217:451470.

Cohen, R.S., S.K. Chung, and D.W. Pfaff 1984 Alteration by estrogen of the nucleoli in nerve cells of the rat hypothalamus. Cell Tissue Res., 235:485-489.

DeBold, J.F., and L.G. Clemens 1978 Aromatization and the induction of male sexual behavior in male, female and androgenized female hamsters. Horm. Behav., 11:401-413.

DeVoogd, T. 1987 Androgens can affect the morphology of mammalian CNS neurons in adulthood. Trends Neurosci., 10:341-342.

DeVoogd, T., and F. Nottebohm 1981 Gonadal hormones induce dendritic growth in the adult avian brain. Science, 214:202-204

DeVoogd, T.J., B. Nixdorf, and F. Nottebohm 1985 Synaptogenesis and changes in synaptic morphology related to acquisition of a new behavior. Brain Res., 329:304-308.

Doherty, P.C., and P. Sheridan 1981 Uptake and retention of androgens in neurons of the brain of the golden hamster. Brain Res., 219:327-334.

Forger, N.G., and S.M. Breedlove 1987 Seasonal variation in mammalian striated muscle mass and motorneurons morphology. $J$. Neurobiol., 18:155-165.

Garcia-Segura, L.M., D. Baetens, F. Naftolin 1986 Synaptic remodelling in arcuate nucleus after injection of estradiol valerate in adult female rats. Brain Res. 366:131-136.

Giegel, J.L., L.M. Stolfi, G.D. Weinstein, and P. Frost 1971 Androgenic regulation of nucleic acid and protein synthesis in the hamster flank organ and other tissues. Endocrinology, 89:904-909.

Gould, E., Woolley, C.S., Frankfurt, M., and B.S. McEwen 1990 Gonadal steroids regulate dendritic spine density in hippocampal pyramidal cells in adulthood. J. Neurosci., 10:1286-1291

Goy, R.W., and B.S. McEwen 1980 Sexual Differentiation of the Brain. MIT Press, Cambridge.

Greenough, W., C.S. Carter, C. Steerman, and T. DeVoogd 1977 Sex differences in dendritic patterns in hamster preoptic area. Brain Res., 126:63-72

Kendrick, K.M., and R.F. Drewitt 1980 Testosterone-sensitive neurons respond to oestradiol but not to dihydrotestosterone. Nature, $286: 67-68$

Krieger, M.S., J.I. Morrell, and D.W. Pfaff 1976 Autoradiographic localization of estradiol-concentrating neurons in the female hamster brain. Neuroendocrinology, 22:193-205.

Kurz, E., D. Sengelaub, and A. Arnold 1986 Androgens regulate the dendritic length of mammalian motorneurons in adulthood. Science, 232:395-398.

Leedy, M.G., M.S. Beattie, and J.C. Bresnaham 1987 Testosterone induced synaptic plasticity of synaptic inputs to adult mammalian motorneuron. Brain Res., 424:386-390.

Lehman, M.N. 1982 Amygdaloid efferents to the bed nucleus of the stria terminalis and the medial preoptic-anterior hypothalamic area controlling male hamster sexual behavior: Behavioral and HRP analysis. Doctoral dissertation, University of Michigan.

Lehman, M.N., and S.S. Winans 1982 Vomeronasal and olfactory pathways to the amygdala controlling male hamster sexual behavior: Autoradiographic and behavioral analyses. Brain Res., 240:27-41.

Lehman, M.N., and S.S. Winans 1983 Evidence for a ventral nonstrial pathway from the amygdala to the bed nucleus of the stria terminalis in the male golden hamster. Brain Res., 268:139-146.

Lehman, M.N., J.B. Powers, and S.S. Winans 1980 Medial nucleus of the amygdala mediates chemosensory control of male hamster sexual behavior. Science, 210:557-560

Lehman, M.N., J.B. Powers, and S.S. Winans 1983 Stria terminalis lesions alter the temporal pattern of copulatory behavior in the male golden hamster. Behav. Brain Res., 8:109-128.

Leuba, G., Jeanprete, N., Krafsik, R., and J.M. Fritschy 1989 Sample size and statistical power in the heirarchical analysis of variance: Applications in morphometry of the nervous system. J. Neurosci Methods, 29:231-239.

Martini, L. 1978 Testosterone metabolism in the brain and the contro of sexual behavior. In: Clinical Psychoneuroendocrinology in Reproduction. Academic Press, London.

Matsumoto, A., P.E. Micevych, and A.P. Arnold 1988 Androgen regulates synaptic input to motorneurons of the adult rat spinal cord. J. Neurosci., 8:4168-4176.

Meisel, R.L., and V.R. Luttrell 1990 Estradiol increases the dendritic length of ventromedial hypothalamic neurons in female syrian hamsters. Brain Research Bulletin 25(1):165-168.

Meisel, R.L., and D.W. Pfaff 1985 Brain region specificity in estradiol effects on neuronal ultrastructure in rats. Mol. Cell. Endocrinol. $40: 159-166$.

Millhouse, O.E. 1981 The Golgi methods. In: Neuroanatomical Tract 
Tracing Methods. L. Heimer and M.J. Roberts, eds. Plenum Press, New York. pp. 311-344.

Mizukami, S., M. Nishizukas, and Y. Arai 1983 Sexual difference in nuclear volume and its ontogeny in the rat amygdala. Exp. Neurol., 79:569-575.

Morin. L.P. and I. Zucker 1978 Photoperiodic regulation of copulatory behavior in the male hamster. J. Endocrinol., 77:249-258.

Nabekura, J., Y. Omura, T. Minami, and Y. Mizuno 1986 Mechanism of the rapid effect of $17 \mathrm{~B}$-estradiol on medial amygdaloid neurons. Science, 233:226-228.

Newman, S.W., R.J. Wood, J.M. Swann, and R.K. Brabec 1991 Androgen and estrogen concentrating neurons in the medial preoptic area and the medial nucleus of the amygdala. Soc. Neurosci. Abs. 17:1411.

Nishizuka, M., and Y. Arai 1983 Regional difference in sexually dimorphic synaptic organization of the medial amygdala. Exp. Brain Res., 213:422-426.

Nishizuka, M., and Y. Arai 1983b Male-female differences in the intraamygdaloid input to the medial nucleus of the amygdala. Exp. Brain Res., 52:328-332.

Nishizuka, M., and D.W. Pfaff 1989 Intrinsic synapses in the ventromedial nucleus of the hypothalamus: An ultrastructural study. J. Comp. Neurol., 286:260-268.

Nottebohm, F. 1980 Testosterone triggers growth of brain vocal control nuclei in adult female canaries. Brain Res., 189:429-436.

Olmos, G., P. Auilera, P. Tranque, F. Naftolin, and L.M. Garcia-Segura 1987 Estrogen-induced synaptic remodelling in adult rat brain is accompanied by the reorganization of neuronal membranes. Brain Res., 425:57-64.

Payne, A.P., and N.K. Bennett 1976 Effects of androgens on sexual behavior and somatic variables in the male golden hamster. Reprod. Fertil., 47:239-244.

Powers, J.B., and M.L. Bergondy 1983 Androgenic regulation of chemoinvestigatory behaviors in male and female hamsters. Horm. Behav., 17:28-44.

Powers, J.B., M.L. Bergondy, and J.A. Matochik 1985 Male hamster sociosexual behaviors: Effects of testosterone and its metabolites. Physiol. Behav., 35:607-616.
Powers, J.B., S.W. Newman, and M.L. Bergondy 1987 MPOA and BNST lesions in male syrian hamsters: Differential effects on copulatory and chemoinvestigatory behaviors. Behav. Brain Res., 23:181-195.

Roselli, C.E., L.E. Horton, and J.A. Resko 1985 Distribution and regulation of aromatase activity in the rat hypothalamus and limbic system. Endocrinology, 117:2471-2477.

Sasaki, M., and A.P. Arnold 1991 Androgenic regulation of dendritic trees of motorneurons in the spinal nucleus of the bulbocavernosus: Reconstruction after intracellular iontophoresis of horseradish peroxidase. J. Comp. Neurol., 308:11-27.

Scheiss, M.C., M. Joels, and P. Shinnick-Gallagher 1988 Estrogen priming affects active membrane properties of medial amygdala neurons. Brain Res., 440:380-385.

Selmanoff, M.K., L.D. Brodkin, R.I. Weiner, and P.K. Siitero 1977 Aromatization and 5a-reduction of androgens in discrete hypothalamic and limbic regions of the male and female rat. Endocrinology, 101:841-848.

Shinoda, K., Y. Hideo, H. Fujita, Y. Osawa, and Y. Shiotani (1989) Screening of aromatase-containing neurons in rat forebrain: An immunocytochemical study with antibody against human placental antigen X-P $\left(\right.$ hPAX-P ${ }_{2}$ ). J. Comp. Neurol., 290:502-515.

Simerly, R.B., B.J. Young, M.A. Capozza, and L.W. Swanson 1989 Estrogen differentially regulates neuropeptide gene expression in a sexually dimorphic olfactory pathway. Proc. Natl. Acad. Sci. U.S.A., 86:4766-4770.

Torand-Allerand, C.D. 1984 On the genesis of sexual differentiation of the central nervous system: Morphogenic consequences of steroid exposure and possible role of alpha-fetoprotein. Prog. Brain Res., $61: 63-98$.

Whalen, R., and J. DeBold 1974 Comparative effectiveness of testosterone, androstenedione and dihydrotestosterone in maintaining mating behavior in the castrated male hamster. Endocrinology, 95:1674-1679.

Witkin, J.W. 1989 Morphology of luteinizing hormone-releasing hormone neurons as a function of age and hormonal condition in the male rat. Neuroendocrinology, 49:344-348. 